sibly only a few can ever succeed in biting a human being at all. Then only a proportion of these will generally have bitten an infected human being; and, again, only a smaller proportion will have bitten an infected person whose blood contains sexual parasites suitable for transmission into a mosquito. Hence the chances usually are that only a very small proportion of all the Anophelines in a place will ever become infected at all. But how many of these will infect healthy persons? A mosquito must live for about ten days at least before the parasites can mature in her body and enter herisalivary glands, and of the small proportion of mosquitoes which may live long enough for this a still smaller proportion are likely to succeed in biting and infecting healthy persons afterwards. Men and mosquítoes may vary in individual resistance to parasites. Both will be infective to each other only at certain times. The general equations for diseases common to two species of hosts conțain fifteen independent constants, or, rather, parameters-namely, the birth-rate, death-rate, immigration, emigration, immunity, infectivity, and recovery ratios. for each species of host, and the contact ratio common to both; and the total proportion of infected individuals of either species must depend on all of these combined in certain mathematical functions.' A special appeal was made to the members of local societies to make a study of the bionomics and distribution of mosquitoes in Britain.

A lecture was given by Mr. Reginald Smith, of the British Museum, on the "Geology of Flint Implements." In the course of many interesting remarks, the Mousterian cave-finds from St. Brelade, Jersey, were illustrated, and compared with certain surfacefinds in England. The hope was expressed that further research in England, which had the advantage of the boulder-clay, might decide man's relation to the glacial period by associating definite types of flintworking with deposits both before and after the most intense glaciation of the country. Much information had been lost to science by inattention to the labelling of specimens as to their place of origin and the position in which found.

Other papers were: "Meteorological Instruments and How to Read Them," by Mr. R. Corless, of the Meteorological Office, and by Lieut. R. W. Ascroft, of the Food Production Department, on "Allotment Pests." Among the afternoon excursions may be mentioned visits to the New Transport Co.'s works at Battersea, where heavy goods are sorted by machinery, on the principle of a central goods clearing-house; to the church of St. Bartholomew the Great; to the classic Charlton Pits, under the guidance of the veteran geologist, Mr. W. Whitaker; to Kew, under that of Lieut.-Col. Sir David Prain and Prof. G. S. Boulger; and to the diving and mine-rescue apparatus works of Siebe, Gorman and Co., under the direction of Dr. J. S. Haldane. The congress was well attended, and apparently justified the council in deciding to hold it this year as usual.

\section{THE TREATMENT OF MALARIA. ${ }^{1}$}

$T$ HE treatment of malaria has engaged the attention of the medical department of the War Office since the outbreak of the war. So soon as cases of this disease began to return to Englanid malaria hospitals were opened, and in certain large hospitals special wards were set apart so that all patients could be concentrated and treated by physicians with special knowledge of malaria. This branch of the medical work was placed under the supervision of Col. Sir

1 Society of Tropical Medicine. (r) An Interim Report on the Treatment of Malaria. (2) Report on a "Discussion on the Treatment of Malaria," Both by Sir Ronald Ross.

NO. 2538 , VOL. IOI]
Ronald Ross, K.C.B., F.R.S., consultant in malaria, War Office, and an interim report now published by this officer gives the results of treatment of a number of cases in four of the hospitals under his control up to the date of publication.

Before commencing treatments, 193 patients who had previously taken quinine, but who had recently discontinued the drug, were observed without further medication with the view of determining approximately the liability to relapse without further treatment. Of these 193 patients, 88 had relapses within twenty-seven days. Owing to illness (unfortunately not specified), 76 . had to be given quinine without continuing the control. After a month, only I5 $_{5}$ per cent. were free from relapse, and were considered well enough to be discharged; 85 per cent. were still showing symptoms of the disease.

Two thousand four hundred and sixty cases of malaria were treated under one or other of the following methods :--

(a) Anti-relapse Quinine Prophylaxis.-Quinine sulphate in small doses by different methods up to 60 grains weekly was given to ro4o cases. A dose of ro grains daily was found to be more effective than one of 5 grains, and was more suitable than one of I5 grains, because, as well as being equally effective, it was better tolerated. Under these treatments relapses were reduced to ro per cent., and even in relapses not so reduced the severity of the paroxysms was diminished.

(b) Short Sterilising' Treatments.-Large doses of quinine sulphate, hydrochloride, or bi-hydrochloride were given daily for seven days, or on consecutive days up to ten days, to 334 cases. A high percentage of these cases relapsed.

(c) Long Sterilising Treatments.-Large doses of the same salts of quinine as in treatments $(b)$ were given daily over long periods, continually, or on consecutive days, or at intervals of several days. Some of these treatments appear to have given the best results, especially the three treatments $(c) I_{5}, 16$, and 17. Two of these were combined in the later stages with iron and arsenic. It may be noted that, in the experience of some observers, much intolerance is shown during the large dosage as here used, without more appreciable diminution of the number of relapses than results from less heroic lines of treatment.

(d) Mixed Treatments, including the administration of drugs other than quinine in the combinations generally used, were given in different doses for varying periods. The drugs used were tartar emetic, acid arsenoids, sodium quinine sulphonate, ethyl quitenine hydrochloride, and collosol quinine. Only a few cases were treated with each drug, as nearly all these relapsed.

Sir Ronald Ross points out that he has not noticed any marlzed superiority in the oral, intramuscular, or intravenous methods of administering quinine. $\mathrm{He}$ advises that a much larger number of cases should be controlled before the efficacy of any particular drug over others can be determined. Obviously it is necessary to observe cases carefully for a much longer period than twenty-seven days after they leave hospital before it is possible to decide what is the actual liability to relapse.

A generous diet is recommended during treatment, with a little stimulant in the form of beer or wine. Opinion seems divided as to whether patients should be kept in bed or not during treatment.

A second paper expressing the opinions of medical officers in the Salonika area as to the value of prophylactic quinine and on the treatment of malaria under different conditions of service was afterwards read by Sir Ronald Ross before the Society of Tropical 
Medicine. Of $\operatorname{Ir}$ officers interrogated on the prophylactic value of quinine in 1o-grain doses twice weekly, their opinions were divided, the majority holding that it was of little or no value, and some even saying that it was detrimental. For treatment in an advanced dressing station for three days, one officer considered that quinine should be given in 80-grain doses daily. The majority (about 63 per cent.) were in favour of 30 grains daily.

For treatment after return to duty subsequent to the above, nine officers advised stoppage of all quinine; seventy-three considered that the drug should be continued for from one to three and a half months in daily doses, according to different opinions, of ro, 20 , or 30 grains. Some recommended gradual reduction of the amount of daily quinine during the same period.

In treating cases following discharge from hospital the treatment advised was much the same, the medical officers expressing the same opinions practically as for cases leaving dressing stations. Subsidiary treatment was recommended by some. Continuance of quinine until the end of the malarial season had also some supporters.

Both these papers include an account of a large amount of work done by many skilled officers, and should serve as a valuable guide to officers and medical men who have charge of malarial cases or intend carrying out further investigation work on this very important subject. It is desirable that an effort be made to ascertain definitely why quinine, so successful in the majority of cases, should fail in others.

An interesting addendum to the first report deals with the excretion of quinine in the urine. It seems that there is a tendency for the excretion of quinine to reach a concentration of $7-\mathrm{II}$ grains per litre of urine. These results obtained no matter what salt was given or how administered, except, perhaps, in the case of the lactate. F. W. O'ConNor.

\section{SCIENTIFIC PROBLEMS OF DISABLED SOLDIERS.}

WE commend to the attention of our readers the April issue of Recalled to Life, a journal edited by Lord Charnwood, and devoted to "the care, reeducation, and return to civil life of disabled sailors and soldiers." Its articles are written by men who are seeking for practical solutions of the problems presented by disabled soldiers-problems which are both medical and sociological. Half of the men who are wounded require special treatment for the restoration of movement to damaged limbs. Great military hospitals have been, and are being, established in various centres throughout the country for the treatment of these crthopædic cases. The establishment of these great "orthopædic" centres has been accompanied by a real educative movement, in which surgeon and soldier have been equally involved. It is true that no new principle of treatment has been introduced; the old methods have been adapted to new conditions and applied on a scale which no one had ever anticipated.

Sir Robert Jones, who contributes an article on "The Problem of the Disabled," was the first to realise that success in the treatment of orthopædic cases was largely a problem of education-to teach soldiers how to bring back lost movements to damaged joints by voluntary and natural movements of the limbs. The introduction of "curative workshops" to military hospitals is one of the most profitable innovations of the war. Of the men treated in orthopædic hospitals about three-fourths return again to military service; the remaining fourth is discharged as untit for further service. It is now the business of the Ministry of Pensions to look after the welfare of that discharged fourth.

Various writers describe the organisations which are being brought into existence to meet the needs, not only of the men discharged from orthopæedic hospitals, but also of the large numbers rejected by the Army on account of a permanent breakdown in health due to exposure in the field, resulting in rheumatism, tuberculosis, disordered action of the heart or of the brain. To meet the needs of the dis. charged unfit the Ministry of Pensions is establishing throughout the country centres of treatment and superintendence. An ideal form of "village centre" for the cure and training of discharged men is described by Mr. Warwick Draper. Major Dundas Grant contributes an article on the training of the deaf soldier. Everywhere the importance of "self-help" is emphasised. Capt. Wilbur C. Lowry, of the Canadian Army Medical Service, while giving an account of the "remedial exercises" practised in the orthopædic gymnasium Granville Canadian Special Hospital, Buxton, mentions the fact that the best teachers are to be found amongst the men who themselves have undergone gymnastic treatment.

\section{CLIMATOLOGY OF PARIS.1}

M FLAMMARION, in the comprehensive report referred to below, not cnly gives a summary of the meteorological conditions in Paris during the years x 915 and I9I6, but also carries the comparison of the seasonal variations of the principal climatic elements back to 1886 : The year $19^{1} 5$ had a mean temperature equal to $10.4^{\circ} \mathrm{C}$., or $0.2^{\circ}$ above the normal, while 1916 was in even closer accordance with the average. The rainfall of 1915 was $574 \mathrm{~mm}$., and of $1916.698 \mathrm{~mm}$., or respectively 3 per cent. and 22 per cent. above the average. The author concludes that "in spite of the frightful intensity of the cannonades, they have exerted no influence on the rainfall in the region of Paris." In Iors less than half the average fell in the months of March, May, and October, the only month showing an excess being December, when, however, the rainfall was more than double the average. This was followed by a very dry January (1916), with less than a quarter of the average. Although somewhat wetter than 1915 , no 'month' in 1916 had an excess of rain greater than one-third of the average.

Some remarkably low barometric pressures are referred to, the most notable being those of November $12-13$, 1915, and November 18, 1916. On the former occasion pressure fell to $723 \mathrm{~mm}$. (28.46 in.), the rise after the minimum being extremely rapid, amounting to $25 \mathrm{~mm}$. ( $0.99 \mathrm{in}$.) in fifteen hours. On the latter date pressure descended to $7 \times 3 \mathrm{~mm}$. $(28.07 \mathrm{in}$.$) , this$ being the lowest reading in the vicinity of Paris since December 24,1821 . In 1915 temperature was somewhat abnormal, the coldest month, November, having a mean temperature $4^{\circ}$ C. lower than that of December. In 1916 the lowest temperature occurred as late as March 8, while the month of June was colder than May. An interesting diagram is given for each year of the daily variations of the various elements of climate, the phases of the moon being also shown, as the author remarks that "the ignorant" still continue to associate weather phenomena with the lunar period.

1 "Rapports sur les Travaux de la Station de Cli $r$ atologie agricole de Juvisy pendant les Années xg15 et igr6." Par M. Camille Flammarion Direcleur de la Station. Pp. 4I. NO. 2538 , VOL. IOI] 